\title{
Elemol from Chamaecyparis obtusa ameliorates 2,4-dinitrochlorobenzene-induced atopic dermatitis
}

\author{
HYUN YANG ${ }^{1}$, EUI-MAN JUNG ${ }^{1}$, CHANGHWAN AHN ${ }^{1}$, GEUN-SHIK LEE ${ }^{2}$, SU-YEON LEE ${ }^{3}$, SEON-HONG KIM ${ }^{3}$, \\ IN-GYU CHOI ${ }^{3}$, MI-JIN PARK ${ }^{4}$, SUNG-SUK LEE ${ }^{4}$, DON-HA CHOI $^{4}$ and EUI-BAE JEUNG ${ }^{1}$ \\ ${ }^{1}$ Laboratory of Veterinary Biochemistry and Molecular Biology, College of Veterinary Medicine, \\ Chungbuk National University, Cheongju, Chungbuk 361-763; ${ }^{2}$ Laboratory of Veterinary Physiology, \\ College of Veterinary Medicine and Institute of Veterinary Science, Kangwon National University, Chuncheon, \\ Gangwon 200-701; ${ }^{3}$ Department of Forest Sciences, College of Agriculture and Life Sciences, Seoul National University, \\ Seoul 151-921; ${ }^{4}$ Division of Wood Chemistry and Microbiology, Department of Forest Products, \\ Korea Forest Research Institute, Seoul 130-712, Republic of Korea
}

Received November 19, 2014; Accepted May 21, 2015

DOI: $10.3892 / \mathrm{ijmm} .2015 .2228$

\begin{abstract}
Chamaecyparis obtusa has been traditionally used as an antibiotic agent and in cosmetics for the prevention of microorganism infection and skin troubles. Atopic dermatitis (AD) is a chronic inflammatory skin disease that encompasses immunologic responses, susceptibility factors and compromised skin-barrier function. Use of plant medicines in therapeutic treatment of AD has recently been suggested as an alternative therapeutic option. The present study examined the effect of elemol, an active component of Chamaecyparis obtusa, on AD using in vivo and in vitro models. RBL-2H3 cells were stimulated with concanavalin $\mathrm{A}$ and dinitrophenyl human serum albumin, and atopic dermatitis was induced in BALB/c mice by topical application of 2,4-dinitrochlorobenzene (DNCB) prior to elemol treatment. The mRNA expression was evaluated by reverse transcription quantitative polymerase chain reaction, and the levels of $\beta$-hexosaminidase and serum immunoglobulin $\mathrm{E}$ (IgE) were examined by ELISA. Histological changes were also performed by microscopy. Elemol attenuated the onset of AD-like skin lesions, reduced serum IgE levels and decreased mast cell infiltration into the dermis and hypodermis. In addition, elemol downregulated the transcriptional expression of several pro-inflammatory cytokines, including TNF- $\alpha$, IL-1 $\beta$, IL- 6 and $\mathrm{I} \kappa \mathrm{B} \alpha$, in the skin of the DNCB-induced animal models of AD. In the RBL-2H3 mast cell line, elemol significantly inhibited the mRNA expression of IL-4 and IL-13, and further attenuated the release of $\beta$-hexosaminidase from mast cells. Histological
\end{abstract}

Correspondence to: Dr Eui-Bae Jeung, Laboratory of Veterinary Biochemistry and Molecular Biology, College of Veterinary Medicine, Chungbuk National University, 52 Naesudongro, Cheongju, Chungbuk 361-763, Republic of Korea

E-mail: ebjeung@chungbuk.ac.kr

Key words: elemol, Chamaecypris obtusa, atopic dermatitis, 2,4-dinitrochlorobenzene examination revealed that elemol significantly ameliorated the DNCB-induced dermal destruction in mice. The results of the present study suggested that elemol may have therapeutic potential in the treatment of AD due to its immunosuppressive effects.

\section{Introduction}

Atopic dermatitis (AD), or eczema, is a chronic inflammatory skin disease with a prevalence of 10-20\% in children and 1-3\% in adults (1). AD has a complex etiology that encompasses immunologic responses, susceptibility factors, environmental triggers and compromised skin-barrier function (2). AD is accompanied by symptoms of pruritus, erythema, edema and xerosis (3), and the underlying mechanisms of these skin diseases are associated with genetic and environmental factors of AD pathogenesis (4). Immunoglobulin E ( $\operatorname{IgE})$, which has a key role in the pathogenesis of allergies, is produced by B-lymphocytes following exposure of a dendritic cell to a foreign antigen under the control of T-helper lymphocytes $(2,4,5)$. The association of $\sim 70-85 \%$ of human AD to IgE hyper-production has been demonstrated and the extent of $\operatorname{IgE}$ sensitization is directly associated with the severity of the disease (6). When two or more molecules of IgE bind to the surface of an immune cell and are simultaneously linked to its specific allergen, the immune cell immediately releases pre-formed inflammatory mediators, including histamine, which induces an immediate allergic response or early phases thereof (2). Following IgE release, the immune cells also synthesize newly formed inflammatory molecules, including leukotriene $\mathrm{D} 4$, prostaglandins and cytokines, including tumor necrosis factor- $\alpha$ (TNF- $\alpha)$, nuclear factor $-\kappa B(N F-\kappa B)$, interleukin-4 (IL-4), IL-5 and IL-13 (2,7-10). Among them, the cytokines IL-4 and IL-13 are known as classic markers of the allergic reaction (10-12). To study the pathogenesis of allergic contact dermatitis, animal models of $\mathrm{AD}$ are used, which are established by induction of a contact hypersensitivity by topical application of 2,4-dinitrochlorobenzene (DNCB) to the skin (13). The allergen DNCB can be internalized by 
local antigen-presenting cells, including dermal dendritic cells and macrophages, is subsequently processed and presented to $\mathrm{T}$ cells in the lymph nodes for activation $(5,14)$, and can cause AD-like symptoms, including eczema, erythema, scaling and hemorrhaging in skin lesions $(2,6,10,15,16)$.

Chamaecyparis obtusa (C. obtusa) is a species of the cypress family and a tropical tree native to the central part of Japan and the Southern part of Korea. Essential oil extracted from $C$. obtusa contains several types of terpene, including monoterpenes, sesquiterpenes and diterpenes. The major constituents in extracts of C. obtusa leaves are sabinene, limonene, bornyl acetate, (+)-borneol, $\alpha$-terpineol and elemol, and those in fruit extracts are myrcene, $\gamma$-terpinene, $p$-cymene, (+)-borneol, $\alpha$-terpineol and $\beta$-caryophyllene $(17,18)$. Although the underlying mechanisms of action of the essential oil of C. obtusa are yet to be fully elucidated, the essential oil or terpenes have been used as anti-microbial agents in foods and cosmetics (18-20). Arima et al (21) demonstrated the anti-bacterial activity of hinokitiol on staphylococci isolated from atopic dermatitis lesions, and hinokitiol caused a decrease in the number of viable bacterial cells from atopic-eczematous lesions. The crude extract of $C$. obtusa reduced allergic reactions in a mouse model of AD (22) and effectively suppressed the serum levels of IgE, pro-inflammatory cytokines and mast cell appearance underneath the dermis and hypodermis (22). C. obtusa, which has been regarded as the most representative medicinal plant, contains active terpene compounds, which may have pharmacological effects (23). However, the underlying mechanisms and precise active components within the composition of $C$. obtusa have remained to be fully identified.

The present study hypothesized that the key active components of $C$. obtusa (elemol, $\beta$-eudesmol and $\gamma$-eudesmol; elemol and $\gamma$-eudesmol were extracted from F5-4, and $\beta$-eudesmol was purchased from Sigma-Aldrich, St. Louis, MO, USA) are the effective in the treatment of symptoms of AD. The anti-atopic properties of the fractions, sub-fractions and principal components of C. obtusa were assessed in in vitro and in vivo models of $\mathrm{AD}$ were assessed in order to test their applicability as pharmaceutical preparations.

\section{Materials and methods}

Essential oil of C. obtusa. C. obtusa was collected from the arboretum of Seoul National University (Gyeonggi, Korea). It was identified and verified by a wood and forest specialist. The yield of the essential oil was 3.6\%. The essential oil from freshly cut needles and stems of $C$. obtusa was obtained by steam distillation using a manufactured apparatus with a condenser. Distillation (EAMS 9501; Misung Scientific Co. Ltd., Seoul, Korea) was continued for $2-3 \mathrm{~h}$ at $100^{\circ} \mathrm{C}$ and the volatile compounds containing the water-soluble fraction were allowed to settle for $20 \mathrm{~min}$. The essential oil layer was separated and finally purified using a microfilter (pore size, $0.45 \mu \mathrm{m}$ ) and the water vapor distillation method (24). C. obtusa oil was then fractionated by silica gel column chromatography for screening and identification of active components of the essential oil. For this, the essential oil (240.40 g) was loaded onto a silica gel column (230-400 mesh, 15x29.5 cm; Merck, Darmstadt, Germany) and eluted with a mixture of hexane and ethyl acetate $(20: 1 \mathrm{v} / \mathrm{v})$ at a flow rate of $20 \mathrm{ml} / \mathrm{min} ; 100-\mathrm{ml}$ fractions were collected in Erlenmeyer flasks. The fractions were pooled into seven groups according to their composition, as visualized by thin layer chromatography [TLC; silica gel (60 mesh)-precoated glassplate; Merck] using 50\% sulfuric acid and 50\% hexane (Sigma-Aldrich), ethyl acetate (Sigma-Aldrich) $(8: 1, \mathrm{v} / \mathrm{v})$ as the developing solvent. After concentrating in a rotary vacuum evaporator (SB-1200; Eyela, Tokyo, Japan), the fractions were labeled 1-7. Fraction 7 was further fractionated by silica gel column chromatography. For this, fraction $7(5 \mathrm{ml})$ was loaded onto a silica gel column (60 mesh, $4.5 \times 31 \mathrm{~cm}$; Merck) and eluted with a mixture of hexane and ethyl acetate $(10: 1, \mathrm{v} / \mathrm{v})$ at a flow rate of $20 \mathrm{ml} / \mathrm{min}$. A total of 43 fractions $(250 \mathrm{ml})$ were collected in Erlenmeyer flasks. The residue adsorbed to the silica gel [silica gel 60 (0.015-0.040 mm), Merck] was re-eluted with 1 liter of ethyl acetate and labeled fraction 44 . The original eluate was pooled into seven fractions according to composition, as visualized by TLC (HX41991254; Merck) using 50\% sulfuric acid and $50 \%$ hexane/ethyl acetate $(8: 1, \mathrm{v} / \mathrm{v})$ as the mobile phase. After concentrating with a rotary vacuum evaporator, the fractions were labeled serially and used in subsequent experiments. A Mass Spectrometry (GC-MS) detector for the analysis of the complex chemical structure of the essential oil was used (stationary phase, DB-5 column $32 \times 0.25 \mathrm{~mm}$; coating thickness of $0.25 \mu \mathrm{m}$; Agilent Technologies, Santa Clara, CA, USA) and the carrier gas was He at $1 \mathrm{ml} / \mathrm{min}$. The working conditions were: injection $300^{\circ} \mathrm{C}$, detector $250^{\circ} \mathrm{C}$. The oven temperature was increased from 40 to 280 at $5^{\circ} \mathrm{C} / \mathrm{min}$, with an initial holding time and a final holding time of $10 \mathrm{~min}$. A split ratio of 5:1 and a mass range from 50 to $800 \mathrm{~m} / \mathrm{z}$ was used. Peak identification was based upon mass spectra comparison with the NIST 08 (National Institute of Standard and Technology) library and with spectra of injected standards. The identification of the retention index of individual compounds was based on comparison of their relative retention times with n-alkane $\left(\mathrm{C}_{8}-\mathrm{C}_{30}\right)$ mixture in DB-5 column, and by matching their mass spectra of peaks from NIST 08 (National Institute Standard Technology) library.

RBL-2H3 cell culture. RBL-2H3 cells (CRL-2256 ${ }^{\mathrm{TM}}$; American Type Culture Collection, Manassas, VA, USA) were cultured in $10 \%$ fetal bovine serum (FBS; Gibco-BRL, Life Technologies, Carlsbad, CA, USA) with Dulbecco's modified Eagle's medium (DMEM) (Gibco-BRL) supplemented with $100 \mu \mathrm{g} / \mathrm{ml}$ streptomycin (Gibco-BRL), $100 \mathrm{U} / \mathrm{ml}$ penicillin (Gibco-BRL) and $5 \mu \mathrm{g} / \mathrm{ml}$ plasmocin ( $\mathrm{pH}$ 7.4; Invivogen, San Diego, CA, USA). RBL-2H3 cells were plated and grown to $70-80 \%$ confluence in six-well plastic tissue culture dishes (Nunc $^{\mathrm{TM}}$, Roskilde, Denmark). RBL-2H3 cells were placed at $37^{\circ} \mathrm{C}$ in a humidified atmosphere of $95 \%$ air and $5 \% \mathrm{CO}_{2}$.

RNA extraction and reverse transcription quantitative polymerase chain reaction $(R T-q P C R)$. RBL- $2 \mathrm{H} 3$ cells were grown on 6 -well plates $\left(1 \times 10^{6}\right.$ cells/well) and experiments were performed $24 \mathrm{~h}$ after plating. The cells were treated with concanavalin A (Con A, $25 \mu \mathrm{g} / \mathrm{ml}$; Sigma-Aldrich) for $1 \mathrm{~h}$, and then washed 4 times with Dulbecco's phosphate buffered-saline (DPBSA; Gibco-BRL). The cells were then treated with cyclosporin A (CsA, $1 \mu \mathrm{g} / \mathrm{ml}$; Sigma-Aldrich) for $1 \mathrm{~h}$. Total RNA was extracted from RBL-2H3 cells and mouse skin using TRIzol reagent (Invitrogen, Life Technologies) according to the manufacturer's instructions. RNA concentrations were measured using 
Table I. Oligonucleotide sequences for quantitative real-time polymerase chain reaction.

\begin{tabular}{|c|c|}
\hline Gene & Primer sequence $\left(5^{\prime}-3^{\prime}\right)$ \\
\hline$T N F-\alpha$ & $\begin{array}{l}\text { F: cctgtagcccacgtcgtag } \\
\text { R: ggagtagacaaggtacaaccc }\end{array}$ \\
\hline$I L-1 \beta$ & $\begin{array}{l}\text { F: gaaatgccaccttttgacagtg } \\
\text { R: ctggatgctctcatcaggaca }\end{array}$ \\
\hline$I L-4$ & $\begin{array}{l}\mathrm{F}: \text { tgatgtacctccgtgcttga } \\
\mathrm{R}: \text { aggacatggaagtgcaggac }\end{array}$ \\
\hline$I L-6$ & $\begin{array}{l}\mathrm{F}: \text { ctgcaagagacttccatccag } \\
\text { R: agtggtatagacaggtctgttgg }\end{array}$ \\
\hline$I L-13$ & $\begin{array}{l}\text { F: ctggaatccetgaccaacat } \\
\text { R: ccatagcggaaaagttgctt }\end{array}$ \\
\hline$I \kappa B \alpha$ & $\begin{array}{l}\text { F: gcaatcatccacgaagagaagcc } \\
\text { R: caggatcacagccagctttcagaag }\end{array}$ \\
\hline$\beta$-actin & $\begin{array}{l}\mathrm{F}: \text { ttctacaatgagctgcgtgtg } \\
\mathrm{R}: \text { accagaggcatacagggaca }\end{array}$ \\
\hline
\end{tabular}

F, forward; R, reverse.

a micro-plate spectrophotometer (Epoch; BioTek Inc., Winooski, VT, USA) at $260 \mathrm{~nm}$. The RNA quality was evaluated by electrophoresis in 1\% agarose gels (MP Biomedicals, Irvine, CA, USA). Total RNA (1 $\mu \mathrm{g})$ was reverse transcribed into first-strand complementary DNA (cDNA) using Moloney murine leukemia virus reverse transcriptase (Invitrogen, Life Technologies) and random primers (9-mer; Takara Bio Inc., Shiga, Japan). Each cDNA sample $(1 \mu \mathrm{l})$ was amplified with $10 \mu \mathrm{l} 2 \mathrm{X} \mathrm{SYBR}^{\circledR}$ Premix Ex Taq ${ }^{\mathrm{TM}}$ (Takara Bio Inc.) and 10 pmol of each primer. Amplification was performed using a 7300 Real-time PCR system (Applied Biosystems, Thermo Fisher Scientific, Waltham, MA, USA) with the following parameters: Denaturation at $95^{\circ} \mathrm{C}$ for $5 \mathrm{~min}$, followed by 40 cycles of denaturation at $95^{\circ} \mathrm{C}$ for $30 \mathrm{sec}$, annealing at $60^{\circ} \mathrm{C}$ for $30 \mathrm{sec}$, extension at $72^{\circ} \mathrm{C}$ for $45 \mathrm{sec}$ and final elongation at $72^{\circ} \mathrm{C}$ for $10 \mathrm{~min}$. Sequences of the oligonucleotide primers as shown in Table I. Relative expression levels in each sample (normalized to that of $\beta$-actin) were determined using RQ software version 1.3 (Applied Biosystems).

$\beta$-hexosaminidase secretion assay. Degranulation was determined by measuring the release of a granule marker $\beta$-hexosaminidase. RBL-2H3 cells were grown on 48 -well plates $\left(2.5 \times 10^{5}\right.$ cells/well) and experiments were performed $24 \mathrm{~h}$ after plating. Cells were then treated overnight with $1 \mu \mathrm{g} / \mathrm{ml} \mathrm{IgE} \mathrm{(Sigma-Aldrich).} \mathrm{For} \mathrm{removal} \mathrm{of} \mathrm{excess} \mathrm{IgE} \mathrm{prior}$ to stimulation, cells were washed four times with extracellular buffer $\left(125 \mathrm{mM} \mathrm{NaCl}, 5 \mathrm{mM} \mathrm{KCl}, 1.5 \mathrm{mM} \mathrm{CaCl}_{2}, 1.5 \mathrm{mM}\right.$ $\mathrm{MgCl}_{2}$ and $20 \mathrm{mmol}$ 4-(2-hydroxyethyl)-1-piperazineethanesulfonic acid, $\mathrm{pH}$ 7.3). The cells were then stimulated with $800 \mathrm{ng} / \mathrm{ml}$ dinitrophenyl human serum albumin (DNP-HSA; Sigma-Aldrich), suspended in $500 \mu 1$ extracellular buffer with $0.1 \%$ bovine serum albumin and incubated at $37^{\circ} \mathrm{C}$ for $1 \mathrm{~h}$. Following incubation, $50 \mu \mathrm{l}$ of the supernatant was incubated with $200 \mu$ l of $1 \mathrm{mM} p$-nitrophenyl $N$-acetyl- $\beta$-D- glucosamine (Sigma-Aldrich) in $0.05 \mathrm{M}$ citrate buffer ( $\mathrm{pH} 4.5$ ) for $3 \mathrm{~h}$ at $37^{\circ} \mathrm{C}$. The enzyme reaction was terminated by addition of $500 \mu \mathrm{l}$ sodium carbonate buffer $(0.05 \mathrm{M}$; pH 10.0) and the optical density of each reaction was read at $405 \mathrm{~nm}$ (SupraMax340; Molecular Devices, Silicon Valley, CA, USA).

Experimental animals. BALB/c mice (7 weeks old, male, weighing $20-25 \mathrm{~g}$; total $n=30, n=5$ per group) were purchased from Koatech (Pyeongtaek, Gyeonggi, Korea), and were allowed to adapt to laboratory conditions (temperature: $20 \pm 2^{\circ} \mathrm{C}$, relative humidity: 50\%, light/dark cycle: $12 \mathrm{~h}$ ) for 1 week. Mice were fed a standard rodent chow diet (Nestlé Purina, St Louis, MO, USA), and the mice were euthanized $24 \mathrm{~h}$ after the last treatment by ether (Sigma-Aldrich) anesthesia. The animal experiments were approved by the Chungbuk National University Animal Care and Use Committee (Chungbuk, Republic of Korea) and all procedures were performed in accordance with the Guide for the Care and Use of Laboratory Animals published by the National Institutes of Health.

Induction of $A D$-like skin lesions in DNCB-treated mice. DNCB (Sigma-Aldrich) dissolved in acetone was used to induce dermatitis in BALB/c mice. Briefly, hair was removed from a $2 \times 4-\mathrm{cm}$ region spanning from the neck to the pelvis and the dorsal skins were sensitized with $100 \mu 12 \%$ DNCB (acetone/olive oil, 4:1) for three days of the first week. After the first sensitization, $100 \mu 10.5 \%$ DNCB was repeatedly applied to the dorsal skin for an additional eight weeks three times a week. At the same time, the vehicle (acetone/olive oil, 4:1; negative control), clobetasol propionate $(\mathrm{CP})$ ointment (a therapeutic control; Glaxo Operations UK Ltd., Greenford, UK) or elemol (2, 5 and 10\%) was evenly applied daily to the entire dorsal skin of the mice three times a week. No substances were applied to the skin surface on the last day of the experiment. The mice were then sacrificed, and the skin, lymph nodes and blood samples were collected for further analysis.

Measurement of serum IgE. Blood samples were collected directly from the plexus venes using a capillary tube at the end of the experiment. Serum was obtained by centrifugation at 3,000 $\mathrm{x} \mathrm{g}$ for $10 \mathrm{~min}$ at $4^{\circ} \mathrm{C}$ and stored at $-70^{\circ} \mathrm{C}$ until use. The serum IgE levels were measured using a mouse $\mathrm{IgE}$ ELISA Ready-Set-Go kit (eBiosciences, San Diego, CA, USA) following the manufacturer's instructions.

Histopathological analysis. The dermis tissue was fixed by inflating the tissue with $10 \%$ formalin (Junsei Chemical, Tokyo, Japan). The tissues were then embedded in paraffin, cut into sections (5 microns) and stained with hematoxylin and eosin (H\&E; Sigma-Aldrich). All tissue samples were examined, photographed and scored in a blinded fashion under light microscopy (BX51; Olympus, Tokyo, Japan). Images were captured using an Olympus DP controller and manager at x100 magnification. To investigate the distribution of mast cells beneath the dermis and hypodermis, the prepared tissues were stained with toluidine blue (Sigma-Aldrich), and images were captured on an Olympus DP controller and manager under a microscope at $\mathrm{x} 400$ magnification. The number of mast cells in a $1-\mathrm{mm}^{2}$ area was counted under a microscope at x400 magnification. 
A

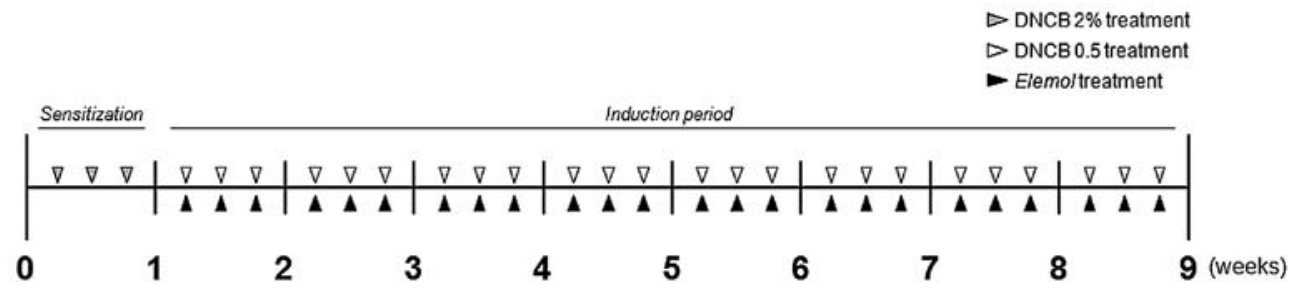

B

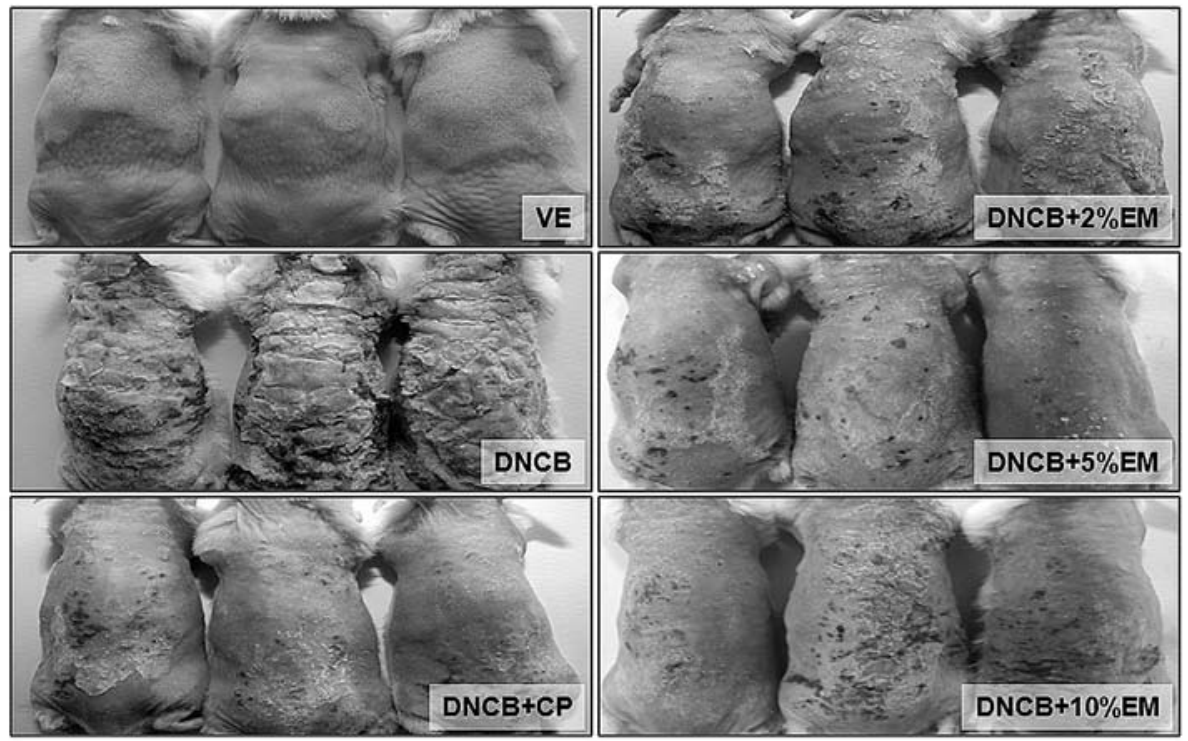

Figure 1. Schedule for DNCB-induced atopic dermatitis in BALB/c mice. (A) DNCB $(0.5 \%, 100 \mu \mathrm{l})$ in acetone/olive oil (4:1) was applied to denuded sections of dorsal skin of mice three times a week. CP or EM (2,5 and 10\%) were topically applied to the same area (three times a week). (B) Macroscopic observations of dorsal skin lesions of EM (2, 5 and 10\%)-treated BALB/c mice. DNCB, 2,4-dinitrochlorobenzene; CP, clobetasol propionate; EM, elemol.

Statistical analysis. Values are expressed as the mean \pm standard error of the mean and were analyzed by one-way analysis of variance followed by Tukey's multiple comparison test. Statistical analyses were performed using GraphPad Prism software v4.0 (GraphPad Software Inc., La Jolla, CA, USA). $\mathrm{P}<0.05$ was considered to indicate a statistically significant difference between values.

\section{Results}

C. obtusa oil ameliorates skin lesions and attenuates increases in serum IgE levels in mice with $A D$. To investigate the anti-allergic effects of elemol extracted from C. obtusa in a mouse model of $\mathrm{AD}$, skin lesions were induced in $\mathrm{BALB} / \mathrm{c}$ mice using multiple topical applications of DNCB for eight weeks (Fig. 1). However, the topical application of elemol $(2,5$ and $10 \%)$ to mice for $1 \mathrm{~h}$ after DNCB application markedly inhibited AD-like skin lesions. Serum IgE levels were increased (up to 3.5-fold) by DNCB treatment compared to those in the vehicle-treated group (VE). The elevated serum IgE levels were decreased in the therapeutic control (CP) treatment, as expected (Fig. 2). The elevated IgE levels were also significantly decreased by treatment with elemol $(2,5$ and $10 \%)$, with the greatest anti-allergenic effect on serum $\mathrm{IgE}$ levels observed with $10 \%$ elemol. These results indicated that elemol attenuated increases of IgE levels in serum, suggesting that this beneficial compound ameliorated the hyper-allergic reaction in the mouse model of $\mathrm{AD}$.
C. obtusa oil decreases skin thickness and mast cell infiltration in mice with $A D$. For observation of skin thickness and immune cell infiltration, skin lesions caused by DNCB treatment were collected and stained with H\&E. DNCB induced an increase in skin thickness compared to that in the vehicle-treated mice, while skin thickness was decreased in elemol $(2,5$ and $10 \%$ ) or CP-treated mice (Fig. 3A). Therefore, AD-like skin treated with elemol at a high concentration $(10 \%)$ has a similar potential for recovery compared to that treated with the positive control, CP. To determine the distribution of mast cells beneath the dermis and hypodermis of AD-like mice, selected tissues were stained with toluidine blue after formalin fixation (Fig. 3B). The number of mast cells was counted under a light microscope and expressed as the number of cells per square millimeter of dorsal skin (Fig. 3C). The infiltration of mast cells increased when mice were treated with DNCB only, while the infiltration was significantly decreased following treatment with 5 and $10 \%$ elemol or with CP (Fig. 3C). These findings suggested that elemol may inhibit the progression of AD-like skin conditions, as demonstrated using the DNCB-induced mouse model of AD.

C. obtusa oil reduces the upregulation of pro-inflammatory cytokines in mice with $A D$. To determine the effect of elemol on the pro-inflammatory cytokines TNF- $\alpha, \operatorname{I\kappa B} \alpha, \mathrm{IL}-1 \beta$ and IL-6, the present study evaluated the transcriptional expression of these cytokines in the skin of mice with DNCB-induced AD. 


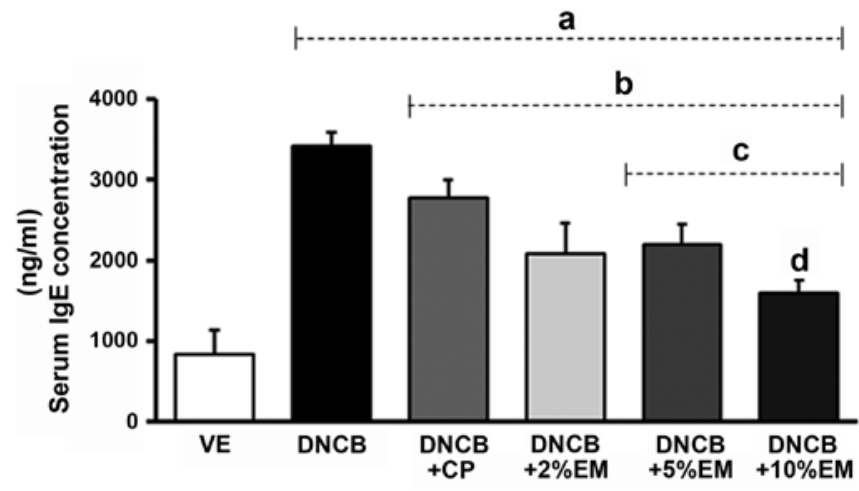

Figure 2. Effects of elemol on serum IgE levels in DNCB-induced mice. The serum IgE levels in BALB/c mice were measured at the end of the experiment (after nine weeks) using an ELISA kit. Groups: VE, vehicle; DNCB, negative control; DNCB + CP, positive control; DNCB + EM ( 2,5 and $7 \%$ ), experimental groups. Values are expressed as the mean \pm standard deviation. ${ }^{\mathrm{a}} \mathrm{P}<0.05$ vs. $\mathrm{VE} ;{ }^{\mathrm{b}} \mathrm{P}<0.05$ vs. DNCB-treated group; ${ }^{\mathrm{C}} \mathrm{P}<0.05$ vs. DNCB $+\mathrm{EM} 2 \%$-treated group; ${ }^{\mathrm{d}} \mathrm{P}<0.05$ vs. DNCB + EM 5\%-treated group. IgE, immunoglobulin E; DNCB, 2,4-dinitrochlorobenzene; CP, clobetasol propionate; EM, elemol.

A

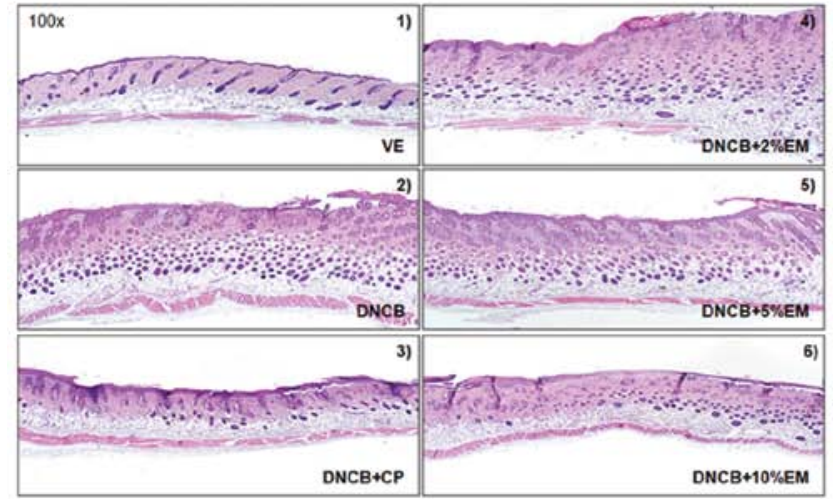

B

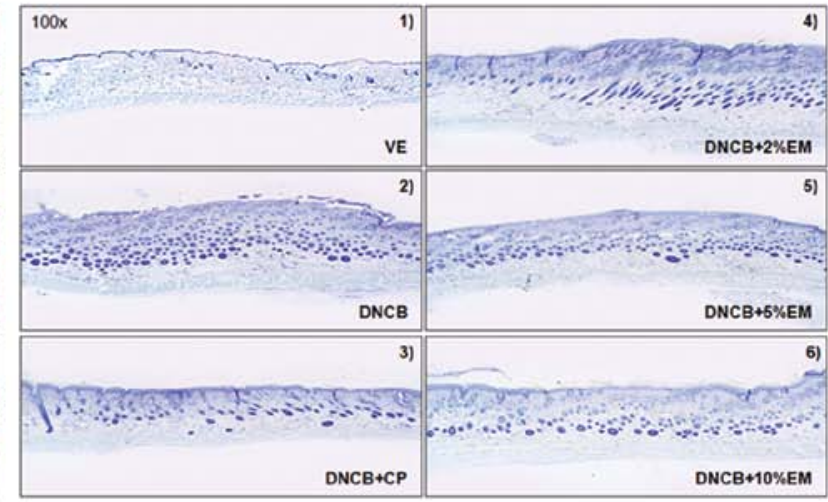

a

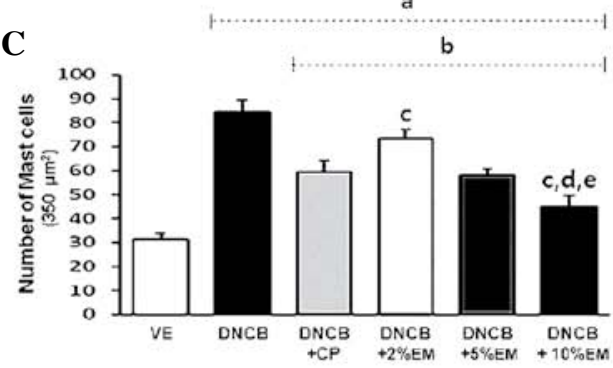

Figure 3. Effects of elemol on histological dorsal skin lesions of DNCB-treated mice. Histological recovery of the dorsal skin lesion and mast cell infiltration beneath the dermis and hypodermis in DNCB- and/or elemol-treated mice. (A) Hematoxylin and eosin stain; (B) toluidine blue stain (magnification, x100). (C) The number of infiltrated mast cells was calculated under a light microscope (magnification, $x 400$ ) and expressed as the number of cells per square millimeter of dorsal skin. Groups: VE, vehicle; DNCB, negative control; DNCB + CP, positive control; DNCB + EM (2, 5 and 7\%), experimental groups. Values are expressed as the mean \pm standard deviation. ${ }^{\mathrm{a}} \mathrm{P}<0.05$ vs. VE; ${ }^{b} \mathrm{P}<0.05$ vs. DNCB-treated group; ${ }^{\mathrm{c}} \mathrm{P}<0.05$ vs. DNCB $+\mathrm{EM} 2 \%$-treated group; ${ }^{\mathrm{d}} \mathrm{P}<0.05$ vs $\mathrm{DNCB}+\mathrm{EM}$ 5\%-treated group. DNCB, 2,4-dinitrochlorobenzene; CP, clobetasol propionate; EM, elemol.

As expected, all cytokines of the skin were induced by DNCB treatment (Fig. 4). The elevated expression of dermal TNF- $\alpha$, I $\kappa \mathrm{B} \alpha$, IL- $1 \beta$ and IL- 6 mRNA was attenuated in the positive control group (DNCB $+\mathrm{CP}$ ). The expression of IL- 6 and $\mathrm{I} \kappa \mathrm{B} \alpha$ was decreased following treatment with elemol at all concentrations as compared with that in the DNCB-induced group; furthermore, the expression of TNF- $\alpha$ and IL-1 $\beta$ mRNA was decreased following treatment with elemol $(2,5$ and $10 \%)$ in a dose-dependent manner compared with that in the DNCBinduced group. These results suggested that elemol may inhibit the expression of pro-inflammatory genes in the skin, which may be the underlying mechanism of the anti-allergenic action of elemol in the mouse model of AD.

Effect of the extracts of $C$. obtusa on atopic dermatitis models. To investigate the anti-allergenic effect of the extracts of $C$. obtusa on the mast cell line RBL-2H3, the cells were treated with the first fractions (F1, F2, F3, F4, F5, F6 and F7) of C. obtusa oil in the presence of DBP-HSA and assessed the secretion of $\beta$-hexosaminidase, as well as the mRNA expression of IL-4 and IL-13. Although the release of $\beta$-hexosaminidase showed a significant decrease following treatment with either 

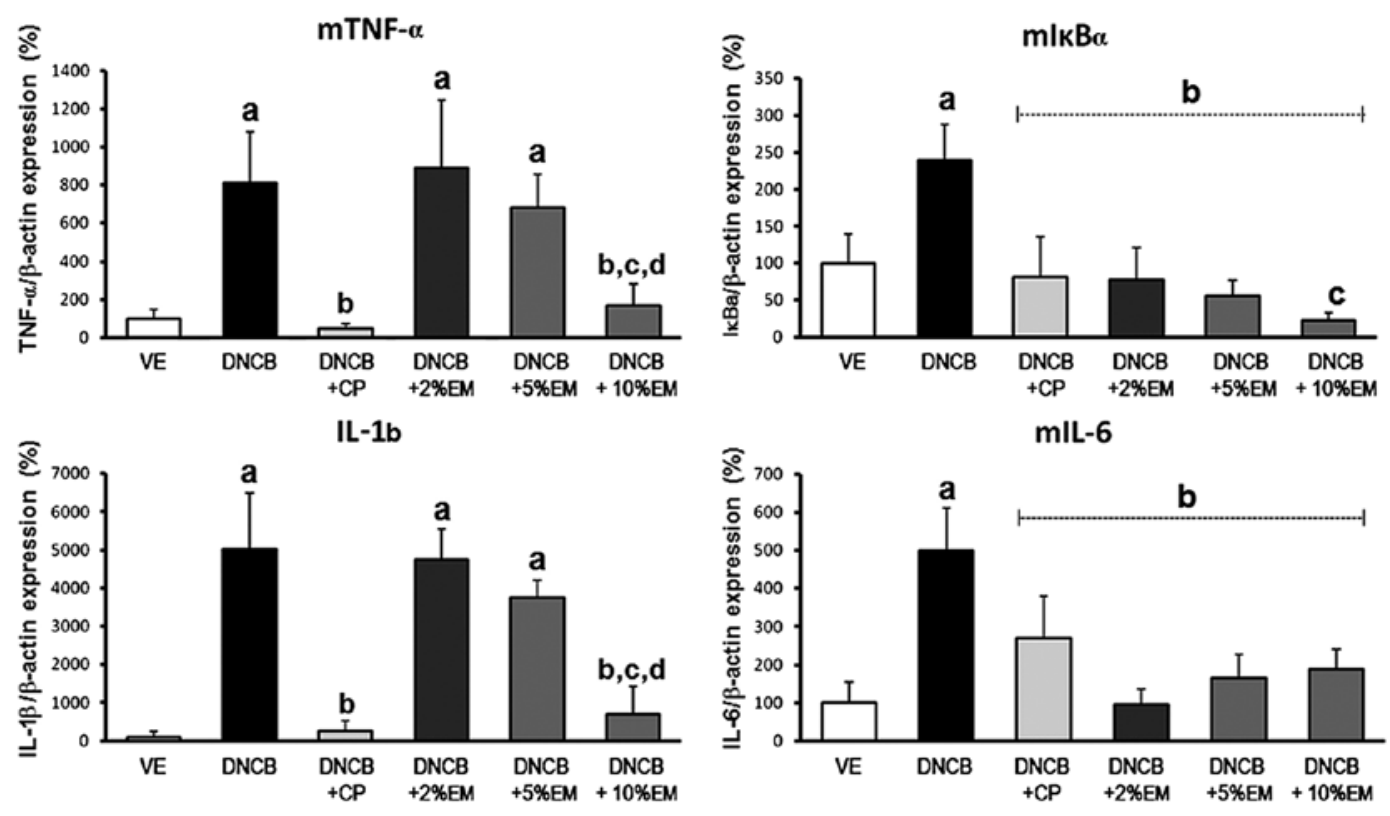

Figure 4. Pro-inflammatory cytokine mRNA expression in dorsal skin lesions of DNCB-treated mice. Isolated mRNA was analyzed by real-time reverse transcription polymerase chain reaction for IL-1 $\beta$, IL-6, I $\mathrm{KB} \alpha$ and TNF- $\alpha$. Results were internally confirmed by the comparative cycle threshold method against $\beta$-actin as the standard gene. Groups: VE, vehicle; DNCB, negative control; DNCB + CP, positive control; DNCB + EM $(2,5$ and $7 \%)$, experimental groups. Values are expressed as the mean \pm standard deviation. ${ }^{\mathrm{a}} \mathrm{P}<0.05$ vs. $\mathrm{VE} ;{ }^{\mathrm{b}} \mathrm{P}<0.05$ vs. DNCB-treated group; ${ }^{\mathrm{C}} \mathrm{P}<0.05$ vs. DNCB $+\mathrm{EM} 2 \%$-treated group; ${ }^{\mathrm{d}} \mathrm{P}<0.05$ vs. DNCB + EM 5\%-treated group. DNCB, 2,4-dinitrochlorobenzene; CP, clobetasol propionate; EM, elemol.

of the fractions (F1 to 7), only treatment with F5 resulted in a dose-dependent decrease in the secretion of $\beta$-hexosaminidase (Fig. 5). mRNA expression of IL-4 and IL-13 was decreased by all fractions (Figs. 6 and 7). Thus, all fractions extracted from C. obtusa had an anti-allergenic effect on the RBL-2H3 cell line and F5 was suggested to be the most effective fraction to attenuate the secretion of $\beta$-hexosaminidase as well as transcriptional regulation of IL-4 and IL-13.

Furthermore, the present study tested the effects of sub-fractions of F5 (F5-1, F5-2, F5-3 and F5-4) on the degranulation and expression of pro-inflammatory cytokines (IL-4 and IL-13) in RBL- $2 \mathrm{H} 3$ cells. DNP-HSA-mediated $\beta$-hexosaminidase secretion was significantly reduced by all sub-fractions, but not at all doses (Fig. 5). In the F5-1 and F5-3 treatment groups, the release of $\beta$-hexosaminidase showed a dose-dependent reduction when compared with that in the negative control group; however, the lowest dosage $\left(10^{-7} \%\right)$ did not affect the release. In the F5-4 treatment group, decreased $\beta$-hexosaminidase release was observed with $10^{-5} \%$ F5-4, while lower doses did not show any effect (Fig. 5). Furthermore, the mRNA levels of IL-4 and IL-13 were inhibited by treatment with sub-fractions of F5 (Figs. 6 and 7). Following treatment with F5-1 and F5-4, the mRNA expression of IL-4 declined in a dose-dependent manner compared with that in the other groups (Fig .6). In the F5-2 and F5-3 treatment groups, IL-4 mRNA expression was also decreased; however, the effects were not dose-dependent. In parallel with IL-4 mRNA expression, the levels of IL-13 mRNA were decreased by all F5 sub-fractions (Fig. 7). IL-13 mRNA expression showed a dose-dependent reduction in the F5-3 and F5-4 treatment groups, while it was reduced in the other groups in a manner that was not dose-dependent. Based on these results, it is suggested that all of the F5 sub-fractions exerted anti-allergenic effects by attenuating increases in $\beta$-hexosaminidase activity as well as IL-4 and IL-13 mRNA expression; in particular, the F5-4 fraction showed stability and efficacy in ameliorating allergic reactions in RBL-2H3 cells.

In addition to the fractions, the principal components of the 5-4 fraction, elemol, $\beta$-eudesmol and $\gamma$-eudesmol, were also evaluated in RBL-2H3 cells, in which an allergic reaction was induced (Fig. 5, lower panel). The $\beta$-hexosaminidase levels were downregulated in the elemol, $\beta$-eudesmol and $\gamma$-eudesmol treatment groups. Eudesmol $\beta$ and $\gamma$ exhibited anti- $\beta$-hexosaminidase activity at high concentration only $\left(10^{-5} \%\right)$; however, elemol had a significant effect at $10^{-6}$ and $10^{-5} \%$ (Fig. 5). These results suggested that C. obtusa oil fractions may alleviate allergic reactions via reduction of $\beta$-hexosaminidase levels as well as IL-4 and IL-13 mRNA expression in RBL-2H3 cells, and that eudesmol and particularly elemol are active components exerting these effects.

\section{Discussion}

$\mathrm{AD}$, also known as eczema, is a type of skin inflammatory disease. A variety of defects in the innate immune system can affect the development and severity of AD. Medications for $\mathrm{AD}$ include oral or topical agents, including emollients, corticosteroids, calcineurin inhibitors and immunosuppressants (12). Numerous natural products are currently being investigated to determine whether they can be used in the treatment of $\mathrm{AD}(2)$. Corticosteriods may be used for severe flares and when the rash covers a large part of the body $(12,25)$. Several corticosteriod ointments are also available for the control of AD-associated symptoms and are often considered to have greater safety and poorer efficacy than oral corticosteroids in the treatment of atopic dermatitis $(12,25,26)$. However, long-term use of oral and topical corticosteriods is associated with a large number of side effects and drug intolerance in the endocrine system of the body $(16,25,27,28)$. To avoid these side effects, certain 

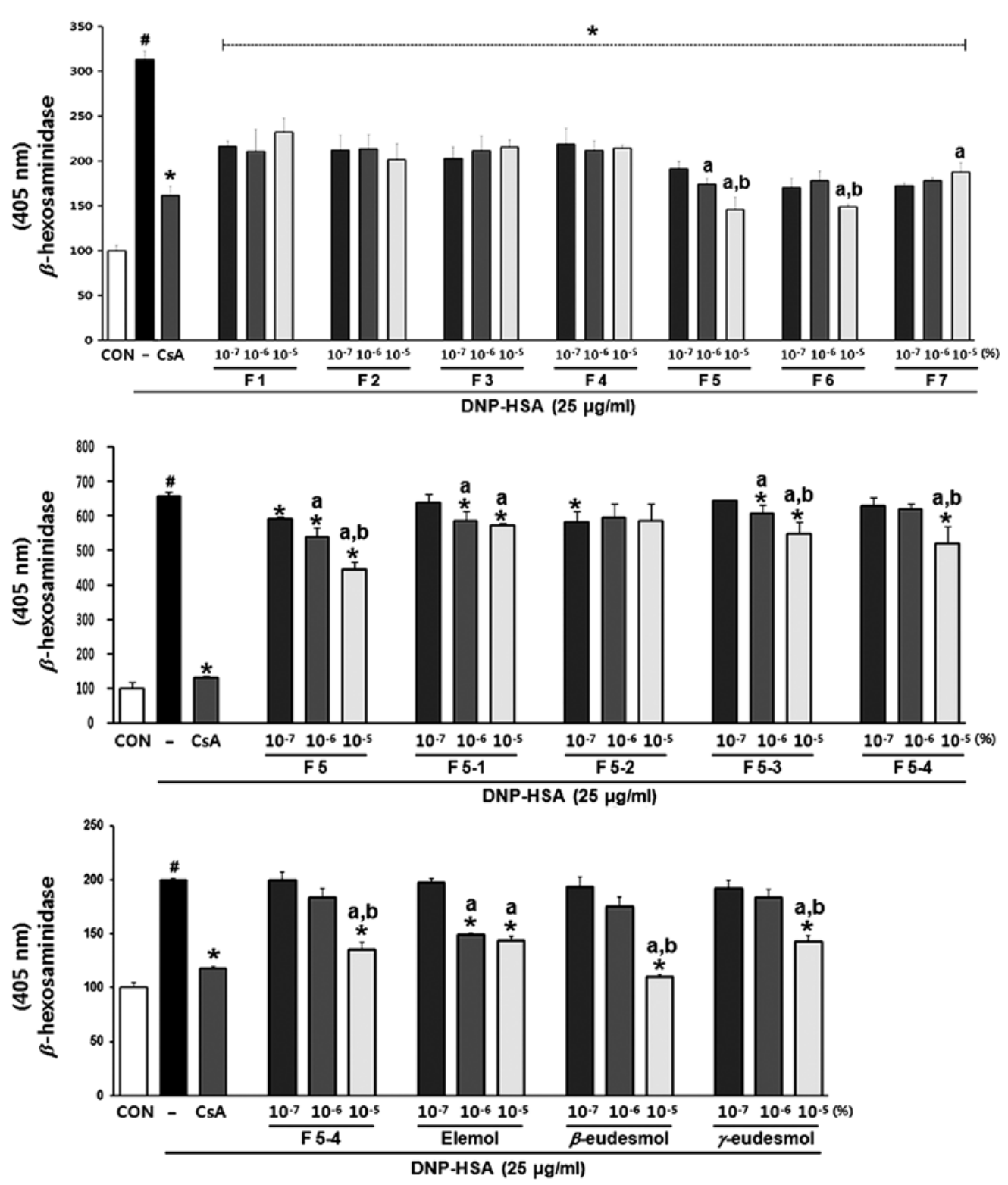

Figure 5. Inhibitory effects of components of Chamaecyparis obtusa on the release of $\beta$-hexosaminidase. RBL-2H3 cells $\left(2 \times 10^{5}\right.$ cells/well) were sensitized with $1 \mu \mathrm{g} / \mathrm{ml}$ DNP-specific immunoglobulin E overnight and treated with varying doses of extract $\left(10^{-7}, 10^{-6}\right.$ and $\left.10^{-5} \%\right)$ for $1 \mathrm{~h}$. Cells were stimulated with $10 \mu \mathrm{g} / \mathrm{ml}$ of DNP-HSA for $1 \mathrm{~h}$. Upper panel, fractions of Chamaecyparis obtusa (F1, F2, F3, F4, F5, F6 and F7); middle panel, sub-fractions of F5 (F5-1, F5-2, F5-3 and F5-4); lower panel, principal components of F5-4 (elemol, $\beta$-eudesmol and $\gamma$-eudesmol). Values are expressed as the mean \pm standard deviation (n=3). ${ }^{\#} \mathrm{P}<0.05$ vs. untreated group $(\mathrm{CON}) ;{ }^{*} \mathrm{P}<0.05$ vs. negative control group (-); ${ }^{\mathrm{a}} \mathrm{P}<0.05$ vs. $10^{-7} \%$ treatment group; ${ }^{\text {b }} \mathrm{P}<0.05$ vs. $10^{-6} \%$ treatment group. DNP-HSA, dinitrophenyl human serum albumin; CON (untreated group), control; CsA, Cyclosporin A; DNP-HSA (-) treatment only (negative control).

medications are prescribed for a short course in an effort to calm the rash.

Compounds from plants have recently been reported as alternative therapeutics for anti-AD treatment, and this type of treatment is expected to prevent the onset of allergic diseases and ameliorate allergic symptoms $(29,30)$. In the present study, the basophilic leukemic cell line RBL-2H3 was sensitized with Con A and mice were induced with DNCB to generate an in vitro and in vivo model of $\mathrm{AD}$, respectively. These models were employed to study the anti-allergenic effects of $C$.obtusa fractions (F1 to 7), sub-fractions (F5-1 to 5-4) and elemol.

The present study examined $\beta$-hexosaminidase release as well as IL-4 and IL-13 mRNA expression from RBL-2H3 cells after treatment with $10^{-7}, 10^{-6}$ and $10^{-5} \%$ of C. obtusa fractions (F1 to 7), sub-fractions (F5-1 to 5-4) and elemol. The release of $\beta$-hexosaminidase showed a significant decrease following treatment with all concentrations of C.obtusa fractions (F1 to 7). In addition, a decrease in IL-4 and IL-13 mRNA expression following treatment with all concentrations of fractions F1-7 was observed. The principal components of C. obtusa, elemol, $\beta$-eudesmol and $\gamma$-eudesmol, were identified from the sub-fraction F5-4, which was particularly potent, using analytical tools. Treatment of stimulated cells with elemol, $\beta$-eudesmol and $\gamma$-eudesmol caused reductions in $\beta$-hexosaminidase release as well as IL-4 and IL-13 mRNA expression to a similar extent to that following treatment with F5-4. However, among the three principal components, the reduction of IL-4 and IL-13 mRNA expression was dose-dependent in the elemol-treatment group only. IL-4 and IL-13 are able to stimulate epithelial cells to produce chemokines, which triggers several key processes of 

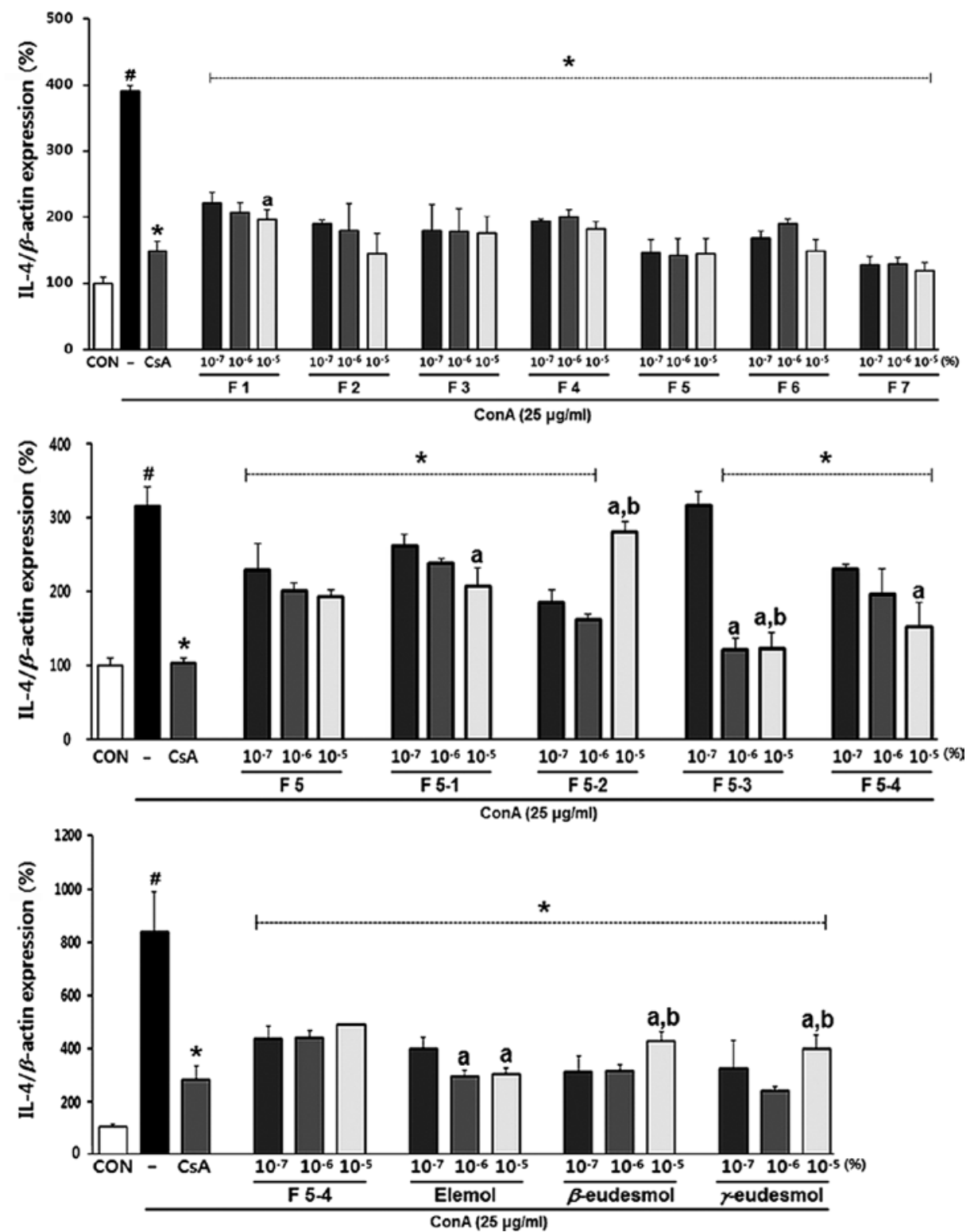

Figure 6. Inhibitory effects of components of Chamaecyparis obtusa on the mRNA expression levels of IL-4 in sensitized RBL-2H3 cells. Upper panel, fractions of Chamaecyparis obtusa (F1, F2, F3, F4, F5, F6 and F7); middle panel, sub-fractions of F5 (F5-1, F5-2, F5-3 and F5-4); lower panel, principal components of F5-4 (elemol, $\beta$-eudesmol and $\gamma$-eudesmol). Values are expressed as the mean \pm standard deviation $(\mathrm{n}=3)$. ${ }^{.} \mathrm{P}<0.05$ vs. untreated group $(\mathrm{CON})$; ${ }^{*} \mathrm{P}<0.05$ vs. negative control group (-); ${ }^{\mathrm{a}} \mathrm{P}<0.05$ vs. $10^{-7} \%$ treatment group; ${ }^{\mathrm{b}} \mathrm{P}<0.05$ vs. $10^{-6} \%$ treatment group. CON (untreated group), control; CsA, Cyclosporin A; DNP-HSA (-) treatment only (negative control).

allergic diseases $(15,22,31)$. The release of $\beta$-hexosaminidase also causes the production of pro-inflammatory and allergenic cytokines, which can potentiate immune responses through the subsequent induction of other $\mathrm{AD}$-associated regulatory processes $(11,22,32)$. The results of the present study suggested that $C$. obtusa fractions may ameliorate allergic reactions via reducing $\beta$-hexosaminidase levels and IL-4, IL-13 mRNA expression, and that elemol is the major active component, at least with regard to the effect on RBL-2H3 cells.

The existence of T-helper (Th)1/Th2 subsets in Th lymphocytes provides a framework for understanding the normal and pathological immune response in allergic responses. In other studies, Th1- and Th2-associated signaling can mutually regulate several immune signaling cascades. Therefore, balancing Th1/Th2 signaling may be fundamental for the treatment of AD $(33,34)$. Therapies using herbal medicines have become increasingly popular in Asia and Europe due to their successful use over extended time periods. A wide variety of phenolic substances derived from plants have been reported to exert marked anti-oxidant and anti-inflammatory activities, which contribute to their chemopreventive potential (35). In addition, volatile components of plants have been reported to exhibit various anti-oxidant activities, which may be responsible for the anti-oxidant effects of these plants (36). In previous studies, C. obtusa oil has been shown to possess anti-microbial and anti-fungal activities (18-20) and has been used to improve the condition of skin with eczematous lesions in AD caused by mite antigens. In a previous study, Joo et al (22) reported that C.obtusa oil attenuated the symptoms of $\mathrm{AD}$ in patients with dry scaly skin lesions by modulating interferon- $\gamma$ and interleukins.

The present study investigated the effects of elemol in a DNCB-induced mouse model of $\mathrm{AD}$ in vivo. The $\mathrm{DNCB}$ - 

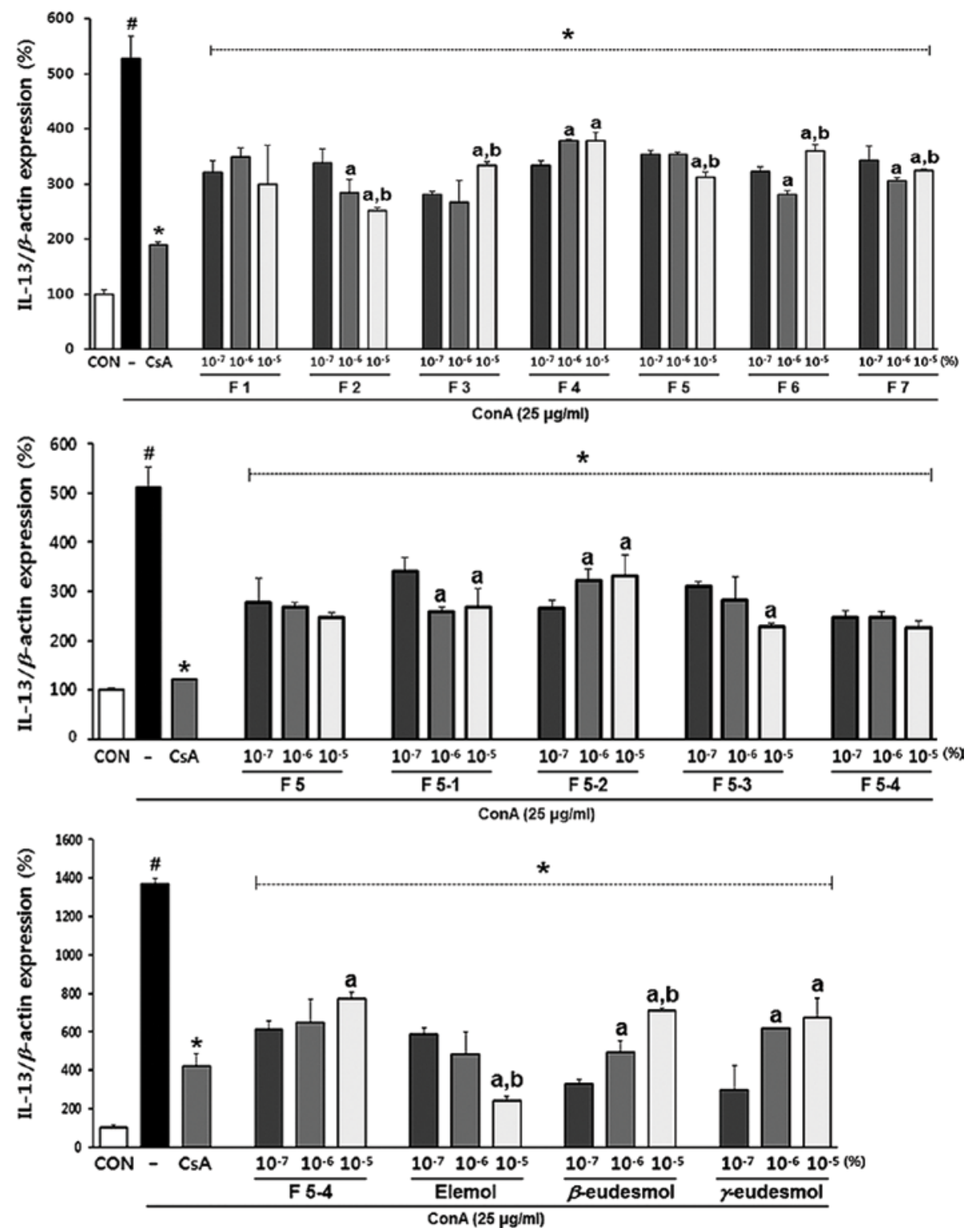

Figure 7. Inhibitory effects of components of Chamaecyparis obtusa on the mRNA expression levels of IL-13 in sensitized RBL-2H3 cells. Upper panel, fractions of Chamaecyparis obtusa (F1, F2, F3, F4, F5, F6 and F7); middle panel, sub-fractions of F5 (F5-1, F5-2, F5-3 and F5-4); lower panel, principal components of F5-4 (elemol, $\beta$-eudesmol and $\gamma$-eudesmol). Values are expressed as the mean \pm standard deviation ( $\mathrm{n}=3$ ). ${ }^{*} \mathrm{P}<0.05$ vs. untreated group (CON); ${ }^{*} \mathrm{P}<0.05$ vs. negative control group (-); ${ }^{\mathrm{a}} \mathrm{P}<0.05$ vs. $10^{-7} \%$ treatment group; ${ }^{\mathrm{b}} \mathrm{P}<0.05$ vs. $10^{-6} \%$ treatment group. CON (untreated group), control; CsA, Cyclosporin A; DNP-HSA (-) treatment only (negative control).

induced serum IgE levels were significantly decreased by application of elemol in the mice with AE. In addition, this treatment resulted in recovery of skin thickness. Topical application of elemol was shown to result in successful elimination of AD-associated symptoms, including skin lesions and mast cell infiltration beneath hypodermis. mRNA expression of cytokines (IL-1 $\beta$, IL- 6 , IкB $\alpha$ and TNF- $\alpha$ ) in the skin lesions of DNCB-treated mice was significantly inhibited by elemol, suggesting that elemol may contribute to the suppression of the stimulation of $\mathrm{T}$ cell-mediated cytokines.

Over the last 50 years, topical corticosteroids have been the primary choice for the treatment of $\mathrm{AD}$; however, due to conditions including skin atrophy, stiriae and perioral dermatitis in sensitive areas (face or skin fold), corticosteroids are not suitable for the long-term treatment of AD (37). Recently, new topical calcineurin inhibitors, including tacrolimus ointment and pimecrolimus cream, have been used for monotherapy treatment of AD to replace conventional treatments (such as corticosteroids); however, their efficacy was not sufficient to successfully treat AD. Therefore, a large number of patients have turned to alternative medicinal approaches (38), which include natural products and herbal medicines. The application of herbal medicines has a long history due to their use in folk medicine, and most well-known medications are derived from plants $(22,23,29)$. Although the mechanisms of action of numerous herbal remedies have not yet been fully elucidated, their clinical benefit has been proven by a large number of scientific studies $(32,38,39)$.

In conclusion, the present study demonstrated the anti-allergenic effects of C. obtusa using an in vitro as well as an in vivo model of AD. One of the key components of C. obtusa, elemol, had potent anti-allergenic activity, particularly in models of AD. Based on the results of the present study, it appears that 
elemol may be a potent therapeutic compound for the treatment of $\mathrm{AD}$, which is effective in controlling the levels of serum $\operatorname{IgE}$ and $\mathrm{T}$ cell-derived cytokines, including IL-1 $\beta, \mathrm{IL}-6, \mathrm{I} \kappa \mathrm{B} \alpha$ and TNF- $\alpha$, in skin lesions of a mouse model of AD.

\section{Acknowledgements}

This study was supported by a grant from the National Research Foundation of Korea (NRF) funded by the Korean Ministry of Education, Science and Technology (MEST; no. 2013R1A2A2A05004582).

\section{References}

1. Adlard BP, Dobbing $\mathrm{J}$ and Sands J: A comparison of the effects of cytosine arabinoside and adenine arabinoside on some aspects of brain growth and development in the rat. Br J Pharmacol 54: 33-39, 1975.

2. Abramovits W: Atopic dermatitis. J Am Acad Dermatol 53 (Suppl 1): S86-S93, 2005.

3. Shimizu N, Dairiki K, Ogawa S and Kaneko T: Dietary whey protein hydrolysate suppresses development of atopic dermatitis-like skin lesions induced by mite antigen in NC/Nga mice. Allergol Int 55: 185-189, 2006.

4. Kang JS, Lee K, Han SB, Ahn JM, Lee H, Han MH, Yoon YD, Yoon WK, Park SK and Kim HM: Induction of atopic eczema/dermatitis syndrome-like skin lesions by repeated topical application of a crude extract of Dermatophagoides pteronyssinus in NC/Nga mice. Int Immunopharmacol 6: 1616-1622, 2006.

5. Grabbe $\mathrm{S}$ and Schwarz T: Immunoregulatory mechanisms involved in elicitation of allergic contact hypersensitivity. Immunol Today 19: 37-44, 1998.

6. Bardana EJ Jr: Immunoglobulin E- (IgE) and non-IgE-mediated reactions in the pathogenesis of atopic eczema/dermatitis syndrome (AEDS). Allergy 59 (Suppl 78): 25-29, 2004.

7. Yu M, Qi X, Moreno JL, Farber DL and Keegan AD: NF-кB signaling participates in both RANKL- and IL-4-induced macrophage fusion: Receptor cross-talk leads to alterations in NF- $\mathrm{B}$ pathways. J Immunol 187: 1797-1806, 2011.

8. Lee SO, Lou W, Nadiminty N, Lin X and Gao AC: Requirement for NF-(kappa)B in interleukin-4-induced androgen receptor activation in prostate cancer cells. Prostate 64: 160-167, 2005.

9. Bhushan S, Hossain H, Lu Y, Geisler A, Tchatalbachev S, Mikulski Z, Schuler G, Klug J, Pilatz A, Wagenlehner F, et al: Uropathogenic $E$. coli induce different immune response in testicular and peritoneal macrophages: Implications for testicular immune privilege. PLoS One 6: e28452, 2011.

10. Georas SN, Guo J, De Fanis U and Casolaro V: T-helper cell type-2 regulation in allergic disease. Eur Respir J 26: 1119-1137, 2005.

11. Sohn EH, Jang SA, Joo H, Park S, Kang SC, Lee CH and Kim SY: Anti-allergic and anti-inflammatory effects of butanol extract from Arctium Lappa L. Clin Mol Allergy 9: 4, 2011.

12. Boguniewicz M and Leung DY: Atopic dermatitis: A disease of altered skin barrier and immune dysregulation. Immunol Rev 242: 233-246, 2011.

13. Garrigue JL, Nicolas JF, Fraginals R, Benezra C, Bour H and Schmitt D: Optimization of the mouse ear swelling test for in vivo and in vitro studies of weak contact sensitizers. Contact Dermat 30: 231-237, 1994.

14. Watanabe H, Unger M, Tuvel B, Wang B and Sauder DN: Contact hypersensitivity: The mechanism of immune responses and $\mathrm{T}$ cell balance. J Interferon Cytokine Res 22: 407-412, 2002.

15. Gong JH, Shin D, Han SY, Park SH, Kang MK, Kim JL and Kang YH: Blockade of airway inflammation by kaempferol via disturbing Tyk-STAT signaling in airway epithelial cells and in asthmatic mice. Evid Based Complement Alternat Med 2013: 250725, 2013.

16. Dharmage SC, Lowe AJ, Matheson MC, Burgess JA, Allen KJ and Abramson MJ: Atopic dermatitis and the atopic march revisited. Allergy 69: 17-27, 2014.

17. Hong CU, Ki CS, Kim NG and Kim YH: Composition of essential oils from the leaves and the fruits of Chamaecyparis obtusa and Chamaecyparis pisifera. J Korean Soc Agric Chem Biotechnol 44: 116-121, 2001 (In Korean).
18. Hong EJ, Na KJ, Choi IG, Choi KC and Jeung EB: Antibacterial and antifungal effects of essential oils from coniferous trees. Biol Pharm Bull 27: 863-866, 2004.

19. Lee HO, Baek SH and Han DM: Antimicrobial effects of Chamaecyparis obtusa essential oil. Kor J Appl Microbiol Biotechnol 29: 253-257, 2001 (In Korean).

20. Trust TJ and Coombs RW: Antibacterial activity of beta-thujaplicin. Can J Microbiol 19: 1341-1346, 1973.

21. Arima Y, Nakai Y, Hayakawa R and Nishino T: Antibacterial effect of beta-thujaplicin on staphylococci isolated from atopic dermatitis: Relationship between changes in the number of viable bacterial cells and clinical improvement in an eczematous lesion of atopic dermatitis. J Antimicrob Chemother 51: 113-122, 2003.

22. Joo SS, Yoo YM, Ko SH, Choi W, Park MJ, Kang HY, Choi KC, Choi IG and Jeung EB: Effects of essential oil from Chamaecyparis obtusa on the development of atopic dermatitis-like skin lesions and the suppression of Th cytokines. J Dermatol Sci 60: 122-125, 2010.

23. Park D, Jeon JH, Kwon SC, Shin S, Jang JY, Jeong HS, Lee I, Kim YB and Joo SS: Antioxidative activities of white rose flower extract and pharmaceutical advantages of its hexane fraction via free radical scavenging effects. Biochem Cell Biol 87: 943-952, 2009.

24. Holtzapple MT and Humphrey AE: The effect of organosolv pretreatment on the enzymatic hydrolysis of poplar. Biotechnol Bioeng 26: 670-676, 1984.

25. Gebben HJ: Topical immunomodulators, such as tacrolimus and pimecrolimus, in the treatment of atopic dermatitis. Ned Tijdschr Geneeskd 149: 1816-1817, 2005 (In Dutch).

26. McClain RW, Yentzer BA and Feldman SR: Comparison of skin concentrations following topical versus oral corticosteroid treatment: Reconsidering the treatment of common inflammatory dermatoses. J Drugs Dermatol 8: 1076-1079, 2009.

27. Furue M, Terao H, Rikihisa W, Urabe K, Kinukawa N, Nose Y and Koga T: Clinical dose and adverse effects of topical steroids in daily management of atopic dermatitis. Br J Dermatol 148: 128-133, 2003.

28. Hengge UR, Ruzicka T, Schwartz RA and Cork MJ: Adverse effects of topical glucocorticosteroids. J Am Acad Dermatol 54: $1-15$, quiz 16-18, 2006.

29. Kawai M, Hirano T, Higa S, Arimitsu J, Maruta M, Kuwahara Y, Ohkawara T, Hagihara K, Yamadori T, Shima Y, et al: Flavonoids and related compounds as anti-allergic substances. Allergol Int 56: 113-123, 2007.

30. Tan HY, Zhang AL, Chen D, Xue CC and Lenon GB: Chinese herbal medicine for atopic dermatitis: A systematic review. J Am Acad Dermatol 69: 295-304, 2013.

31. Munitz A, Brandt EB, Mingler M, Finkelman FD and Rothenberg ME: Distinct roles for IL-13 and IL-4 via IL-13 receptor alpha1 and the type II IL-4 receptor in asthma pathogenesis. Proc Natl Acad Sci USA 105: 7240-7245, 2008.

32. Wang W, Zhou Q, Liu L and Zou K: Anti-allergic activity of emodin on IgE-mediated activation in RBL-2H3 cells. Pharmacol Rep 64: 1216-1222, 2012.

33. Heinzel FP, Sadick MD, Holaday BJ, Coffman RL and Locksley RM: Reciprocal expression of interferon gamma or interleukin 4 during the resolution or progression of murine leishmaniasis. Evidence for expansion of distinct helper $\mathrm{T}$ cell subsets. J Exp Med 169: 59-72, 1989.

34. Grewe M, Bruijnzeel-Koomen CA, Schöpf E, Thepen T, Langeveld-Wildschut AG, Ruzicka T and Krutmann J: A role for Th1 and Th2 cells in the immunopathogenesis of atopic dermatitis. Immunol Today 19: 359-361, 1998.

35. Surh YJ, Na HK, Lee JY and Keum YS: Molecular mechanisms underlying anti-tumor promoting activities of heat-processed Panax ginseng C.A. Meyer. J Korean Med Sci 16 (Suppl): S38-S41, 2001.

36. Jang HW, Ka MH and Lee KG: Antioxidant activity and characterization of volatile extracts of Capsicum annuum L. and Allium spp. Flavour Fragrance J 23: 178-184, 2008.

37. Thaçi D: Long term management of childhood atopic dermatitis with calcineurin inhibitors. Hautarzt 54: 418-423, 2003 (In German).

38. Vender RB: Alternative treatments for atopic dermatitis: A selected review. Skin Therapy Lett 7: 1-5, 2002.

39. Yoon S, Lee J and Lee S: The therapeutic effect of evening primrose oil in atopic dermatitis patients with dry scaly skin lesions is associated with the normalization of serum gamma-interferon levels. Skin Pharmacol Appl Skin Physiol 15: 20-25, 2002. 